\title{
EL MATRIMONIO INFANTIL EN MÉXICO
}

\section{Lic. Rocío del Carmen Olán Campos ${ }^{1}$ \\ Dra. Josefina De la Cruz Izquierdo ${ }^{2}$}

\begin{abstract}
Child marriage is a major social phenomenon in which children and adolescents are abused and exposed. Their rights are violated and they are exposed to both physically and psychologically dangers, since it is a

assimilate from one day to another, so children who suffer from this violation have serious problems developing before society because they are prevented from physical freedom, as well as the ability to decide their future for themselves.
\end{abstract} forced marriage between an adult and a minor. It is a disorder where drastically change from a child or teenager to play the role of and adult with a series of responsibilities not suitable for their age. The child not only have to be inserted into adulthood but they also develop as wives or husbands, even in mothers without having reached adulthood or without even knowing what marriage and motherhood implies. Child marriage is a serious violation of the Rights of the Child, and girls are more vulnerable to this situation, as they have to bear the obligation to be both wife and marital rape is increasing when they are in. Leaving childhood and moving into adulthood is not easy, nor is it possible to

Keywords: Marriage, children, responsibilities, motherhood, rape.

\section{Introducción}

El matrimonio infantil es uno de los delitos más grandes que violan los derechos de los niños y niñas. Desafortunadamente poco se habla de esta problemática que se desencadena en la sociedad. Se entiende entonces al matrimonio infantil como aquella unión marital de un menor de edad ya sea niña, niño o adolescente con una persona mayor de edad, donde una de las partes es forzada a unirse con la otra por lo que no hay voluntad, entonces pasa a ser forzado (Cuadrado, 2017). A diferencia del matrimonio que se celebra entre

\footnotetext{
${ }^{1}$ Licenciada en Derecho por la Universidad Juárez Autónoma de Tabasco y Egresada de la Maestría en Derecho por la misma institución.

${ }^{2}$ Doctora en Educación y Profesora Investigadora en la Universidad Juárez Autónoma de Tabasco, en México
} 
adultos, en el caso de los niños, éstos no tienen la madurez para comprender el acto que se está celebrando, por lo que en muchas ocasiones dejan de disfrutar su infancia para madurar de manera tajante.

En el caso del matrimonio infantil, quienes sufren este tipo de uniones son los niños, los cuales han sido definidos en la Convención de los Derechos del Niño (UNICEF, Convención sobre los Derechos del Niño, 2006) como todo ser humano menor de dieciocho años de edad, salvo que, en virtud de la ley que le sea aplicable, haya alcanzado antes la mayoría de edad.

Al respecto, las Reglas mínimas de las Naciones Unidas para la Administración de la Justicia de Menores (Reglas de Beijing) (UN, 2016) establecen que menor es todo niño o joven que, con arreglo al sistema jurídico respectivo puede ser castigado por cometer un delito en forma diferente a un adulto; y las Reglas de Tokio establece el límite de dieciocho años de edad.

En ese mismo sentido, la Organización Internacional del Trabajo considera niños y niñas a los menores de 14 años, mientras que después de esta
28

edad hasta los dieciocho años son adolescentes.

Por ello, al referirse a la condición jurídica y derechos humanos del niño en América, la Corte Interamericana de Derechos Humanos (2002) detalló que millones de niños viven en condiciones de pobreza y marginación, por lo que son víctimas del olvido y de las fallas estructurales del sistema, al no establecer políticas nacionales e internacionales de protección.

Esto se agudiza todavía más en el caso del matrimonio infantil, pues una persona mayor de edad (de 18 años en adelante), tiene la madurez de elegir cómo y con quién iniciar su vida matrimonial, tal y como lo establece el Código Civil Federal (Diputados, Código Civil Federal, 2019); sin embargo, en el caso de las niñas, niños y adolescentes, éstos no han alcanzado su normal desarrollo y no han alcanzado la suficiente madurez para comprender el compromiso que adquieren a través de la figura del matrimonio, aunado a que muchas de esas uniones vivirán en un clima de violencia y de discriminación, además de vulneración de todos sus derechos. 
Algunos datos

La unión de un menor de edad con una persona adulta trae repercusiones muy graves para la víctima ya que afecta varios ámbitos de la persona: emocionalmente, físicamente, la educación, la integridad y la forma en que se desarrolla con la sociedad, lo que a su vez da paso al aumento de la discriminación y violencia de género; pero también trae consigo consecuencias exteriores a estos como lo son el abandono de la escuela, embarazos no deseados o prematuros, mortalidad de la madre en este caso menor de edad, pobreza en la sociedad, infecciones de transmisión sexual, trabajo infantil y limitaciones en el proyecto de vida del niño o adolescente (García Gómez, 2017).

Se considera que hay factores principales que desencadenan el matrimonio infantil tales como: la falta de empleo y oportunidades, la pobreza, la desigualdad de género, la exclusión y la cultura que desde hace mucho tiempo atrás a jugado un papel muy importante en los derechos humanos, pues con mucha facilidad es ahí donde se vulneran los derechos de las personas.
De acuerdo a la UNICEF (s.f.), el $36 \%$ de las mujeres cuyas edades oscilan entre 20 y 24 años se casaron o vivían en pareja, antes de que hubieren cumplido los 18 años; mientras que 14 millones de adolescentes de entre 15 y 19 años dan a luz cada año. Éstas últimas tienen más probabilidades de morir durante el embarazo o el parto a diferencia de las que han alcanzado los 20 años, cuyas probabilidades disminuyen.

Se estima que mundialmente cada tres segundos se obliga a una niña a casarse y el $14 \%$ de las niñas que viven en México se casarán antes de cumplir los 15 años. De acuerdo con el INEGI, entre 2000 y 2015 se han casado más de 9,500,000 niños. En cuanto a nacimientos que provienen de madres menores de edad, del 2000 al 2015 es de cerca de tres millones, y de ellas, 4,871 tenían tan solo 10 años al momento de dar a luz (Navarrete, 2017). Lo anterior es alarmante, pues indica que hay más de 6.8 millones de mujeres, de entre 15 a 54 años que contrajeron matrimonio antes de $\operatorname{los} 18$ años.

Existen todavía países en los que los padres deciden sobre el matrimonio de las hijas por intereses o 
necesidades económicas, como en el caso de Tanzania, Uganda y Kenia; de lo que deriva que África tenga la mayor tasa de matrimonio infantil en el mundo. Los progenitores permiten estos matrimonios pues consideran que de esta manera proporcionan a sus hijas una tutela masculina que pueda protegerlas de agresiones sexuales, de evitar embarazos sin estar casada o bien aseguran que la mujer obedecerá al marido.

En países como Mali, de acuerdo a su código familiar vigente, las mujeres tienen la obligación de obedecer a sus maridos; en Níger, la edad media de matrimonio es de 15.8; en Malawi, 4 de cada 5 niñas casadas no ha terminado la educación primaria; en Mozambique, las niñas abandonan la escuela debido a la violencia emocional, física y sexual, lo que les lleva a casarse. Asia no está exenta, pues cuenta con la segunda tasa de incidencia más alta del mundo. En este continente, el $46 \%$ de los niños y niñas contraen matrimonio antes de cumplir los 18 años; en Bangladesh, el $73 \%$ de las mujeres casadas lo hicieron cuando eran niñas; en Indonesia, el $45.5 \%$ de las personas encuestadas respondieron que estaban de acuerdo con que las mujeres se casaran antes de los 18 años pues consideran que hay muchas ventajas (Plan Internacional, 2015).

En los países asiáticos, el hombre debe casarse porque es necesario para satisfacer sus necesidades sexuales, emocionales y reproductiva, por lo que el casarse les permite obtener una esposa que cumplirá con sus tareas del hogar y el cuidado de los padres. Una mujer soltera es motivo de rumores sobre ella, se pone en juego su reputación y la gente comenzará a pensar que tiene aventuras amorosas; a diferencia del hombre, el cual puede permanecer soltero sin ninguna restricción. A lo anterior se agrega el hecho de que el género y la sexualidad promueven la subordinación social y económica de las niñas y mujeres con respecto a los varones. En estos lugares se considera que la esposa debe estar al servicio de su marido y éste debe ser el jefe de la familia (Plan Internacional, 2015).

\section{El caso de México}

México ha adoptado diversos instrumentos internacionales, como la Convención sobre los Derechos del Niño y la Convención para la Eliminación de Todas las Formas de Discriminación 
contra las Mujeres (CEDAW) en las que se ha recomendado para el Estado que la edad mínima para contraer matrimonio se fije en los 18 años. Y aunque existen leyes que permiten que los adolescentes se casen con la autorización de los tutores, padres o familiares cercanos, se requiere que sea bajo un motivo grave y justificado, siendo el representante del Estado el que decida sobre la realización del acto solemne.

En la Ley General de los Derechos de las Niñas, Niños y Adolescentes se fija la edad de 18 años como la edad mínima para contraer matrimonio y hasta la fecha, sólo 24 Estados han armonizado esta disposición y los 8 restantes están en proceso.

En México es alarmante que en el 2014 , el $10.4 \%$ de muertes maternas correspondían a mujeres menores de edad, lo que demuestra que su vida sexual la iniciaron antes de los 18 años (Kánter Coronel, 2018).

Según datos de la Encuesta Nacional de la Dinámica Demográfica en el 2018, la tasa global de fecundidad en las localidades rurales era de 2.51 hijos por mujer, mientras que en las localidades urbanas es de 1.94 hijos por mujer lo que nos da por resultado que efectivamente los factores antes mencionados son los que desencadenan esta problemática social, pues incluso en algunos lugares el matrimonio infantil lo ven como un método de adquirir ganancias monetarias a través del menor; principalmente porque algunos padres consideran que tienen derecho a vender a sus hijas.

En la ENADID 2018 (INEGI, 2019), la tasa global de fecundidad en las mujeres con algún grado de primaria era de 2.82 hijos por mujer, y en las mujeres con algún grado de medio superior y superior es de 1.75 hijos por mujer lo que demanda más pobreza y poco crecimiento económico en las comunidades .

La muerte materna en madres menores de 15 años se da en países de ingresos bajos, aunque no se deja atrás los países medio desarrollados. Aproximadamente 70.000 jóvenes mueren en el embarazo o durante el parto. La mayoría de las niñas y adolescentes que quedan embarazadas tienden a ser de familias de bajos recursos con un déficit de alimentación.

El problema no es sencillo y es grave. El Fondo de Población de las Naciones Unidas publicó el libro 
"Maternidad en la niñez" (Williamson, 2013) en el cual su autora recoge algunos testimonios, dentro del que destaca el realizado por Clarisse, de 17 años la cual narra:

“Tenía 14... Mi mamá y sus hermanas empezaron a preparar la comida y mi papá nos pidió a mis hermanos, a mis hermanas y a mí que nos pusiéramos la mejor ropa porque íbamos a tener una fiesta. Como no sabía qué sucedía, festejaba como todos los demás. Ese día me enteré de que era mi boda y que debía irme con mi marido. Intenté escapar, pero me atraparon. Así que me encontré con un marido tres veces mayor que yo... Se suponía que este casamiento me salvaría del desenfreno. La escuela había terminado, así de simple. Diez meses después, estaba con un bebé en mis brazos. Un día decidí escapar, pero acepté quedarme con mi marido si me dejaba volver a la escuela. Volví a la escuela. Tengo tres hijos y estoy en séptimo grado."

Lo que constituye un claro ejemplo de que en comunidades menos desarrolladas el matrimonio infantil se ve como una salida a la situación que se vive; sin embargo, el riesgo por muerte materna en madres menores de 15 años es mucho mayor al que sufren las mujeres mayores; principalmente porque durante el embarazo y el parto se incide mayormente en las causas de muertes de adolescentes.

Se está frente a un problema social que se expande por todo el país, en cada Estado hay índices de matrimonio infantil forzado, violencia de género, discriminación etc. Por lo que pasa a formar parte de un delito en el cual hay que trabajar mucho para erradicarlo; principalmente porque se afecta a un grupo de la sociedad considerado vulnerable y que no cuenta con la madurez para comprender la importancia del compromiso que están adquiriendo. Es necesario que se fijen políticas públicas que atiendan las causas estructurales; y aunque la modificación de las leyes es indispensable, se requiere un cambio cultural real que involucre a las familias y a las instituciones.

\section{El matrimonio infantil.}

Edgar Baqueiro (1997) define al matrimonio como un acto solemne entre un hombre y una mujer, -dos personas de distinto sexo., realizada voluntariamente, con el propósito de crear una comunidad de vida entre ellos y una convivencia permanente. Es 
considerado un acto voluntario realizado ante una persona autorizada por el Estado para celebrarlo.

Para su realización se recurre a ritos o formalidades legales que tienen como finalidad, dar certeza sobre la voluntad de los contrayentes. A raíz del matrimonio se genera el concepto de familia, el cual ha evolucionado a través del tiempo; a tal grado que, en México, el matrimonio se puede realizar entre parejas del mismo sexo.

\section{Miguel Carbonell (2006)} asegura que el concepto de familia, antes de ser jurídico, es sobre todo sociológico, pues la familia es un grupo de personas ligadas directamente por el parentesco, cuyos integrantes asumen la responsabilidad del cuidado de los hijos.

Ahora bien, desde el punto de vista teleológico, el matrimonio ha sido definido como la sociedad física $\mathrm{y}$ espiritual, excluyente e indisoluble, determinada por el consentimiento del varón y de la mujer, con la finalidad de procrear y educar a la prole, elevada por Cristo a la naturaleza de sacramento. Santo Tomás de Aquino coincidía con la idea de que era una unión indiscutible y marital entre personas legitimas que observan una indivisible comunidad de vida (Barros Álvarez, 2001). Esta definición no varió de la dada por Ulpiano (Abundis Rosales \& Ortega Solis, 2010) quien insistía en que el matrimonio o las nupcias eran la unión del hombre y la mujer que contiene la comunión habitual e indivisible de vida .

En el Código Napoleónico (Hernández, 2012), se definió como la unión del hombre y la mujer para perpetuar la especie, para socorrerse y asistirse mutuamente, y para sobrellevar el peso de la vida además de compartir un destino común. Definición que se conservó hasta nuestros días.

Sin embargo, existen dos elementos indispensables para que exista el matrimonio: la voluntad de las partes de querer formar una familia y el deseo de crear un estado permanente de vida entre los cónyuges, compartiendo deberes y facultades, derechos y obligaciones en común, con la finalidad de proteger los intereses colectivos y superiores de la familia, como lo son la procreación, alimentación, educación y protección de los hijos con quienes se establecen además, derechos y obligaciones recíprocos (Galindo, 1989). Por ello, el matrimonio es considerado un acuerdo de voluntades en 
el cual se requiere el consentimiento de las partes para que nazcan derechos que son inmutables y sus efectos esenciales no dependen de la voluntad arbitraria de las partes. Esto es trascendental porque en el matrimonio, la voluntad de las partes es la que fija los derechos y obligaciones de cada una de ellas y si bien es cierto, en el matrimonio existe un acuerdo de voluntades, los derechos y obligaciones ya están establecidos dentro de la ley, y los consortes sólo son libre para escoger el régimen matrimonial sobre el que establecerán su sociedad.

Por lo anterior, es claro que el matrimonio infantil está estrechamente ligado a un problema de derechos humanos, puesto que una niña que contrae matrimonio y posteriormente queda embarazada se ve obligada a dejar los estudios negándosele así el derecho a la educación. A una menor de edad se le limita el uso de métodos anticonceptivos negándole así el derecho a la salud; a un menor de edad poco se le habla de sexualidad, negándoles también el derecho a estar informado. $\mathrm{Y}$ el problema no es solo de las comunidades o de las familias que viven fuera de la ciudad en las zonas alejadas o apartadas, sino también las autoridades tienen como responsabilidad proteger tanto al menor como los derechos de estos.

Derivado de la división de género que está implantada en la sociedad, el hombre es sobre el que descansa la responsabilidad proveer económica, jurídica y socialmente a la mujer, mientras que sobre ella está la obligación de proteger a los hijos y la fundación de la familia. Sin embargo, si bien esta subordinación está cambiando en la actualidad, no es posible concebirla en el matrimonio infantil ya que, por la corta edad de los contrayentes y su estado de indefensión, la relación que existe en el reparto de roles es más severa. El matrimonio impone deberes y obligaciones y en el caso de las niñas, éstas deben de asumir que en su vida se incluirán las relaciones sexuales, la maternidad y la crianza además de las labores en el hogar.

El matrimonio infantil es considerado la unión de dos personas en la que al menos una de ellas es menor de 18 años. Este fenómeno debe verse desde tres puntos de vista: como una tradición en la que se sujeta a la esclavitud a la niña que es obligada a contraer nupcias, quedando con este acto obligada a 
prácticas serviles; la de género, que considera al matrimonio como una forma de violencia y que afecta la salud de las niñas y adolescentes que están dentro del mismo; y la de los derechos de los niños, que supone una obligación estatal para evitar que se cometan este tipo de actos que van en detrimento de los menores de edad (Lisa, 2017).

Por ello, es necesario trabajar en sociedad, pues bien, la prioridad será acabar con el matrimonio infantil en conjunto con las leyes y los sistemas normativos de regulación para proteger a los menores de edad y a todas las personas que sean vulnerables de formar parte de este problema ayudando así el crecimiento de los niños y jóvenes en su proyecto de vida.

Lo anterior de acuerdo a lo que ha establecido la Asamblea General de las Naciones Unidas, la cual ha indicado que algunas leyes y antiguas costumbres que están directamente vinculadas con el matrimonio y la conformación de una familia, constituyen una violación a los principios de los derechos humanos; de igual forma, la Convención suplementaria sobre la abolición de la esclavitud, la trata de esclavos y las instituciones y prácticas análogas a la esclavitud de 1957 equiparó 35 matrimonio forzado a la esclavitud debido a que sobre los cónyuges se ejerce el derecho de propiedad. Y es que el matrimonio con una persona que no ha alcanzado su mayoría de edad afecta

Además de trabajar en sociedad es necesario y urgente fortalecer el marco legislativo para que sea adecuado y normativo a su vez, puesto que al ser inadecuados y no tener una severidad hay más tendencia a ser violado y a no llevarse a cabo su aplicabilidad de una manera correcta lo que perpetua la práctica del matrimonio infantil.

La mayor parte de los países ha trabajado en esto, pero hay grietas que corregir ya que muchas de sus leyes no son aplicadas de manera efectiva; además, las figuras de representación (autoridades) no están lo suficientemente capacitados para trabajar de cerca con las víctimas ya que demuestran déficit en la forma en que abordan el caso. Si se revisa la legislación, ésta tiene vacíos enormes referente al tema por lo que la problemática sigue en aumento. Por ejemplo, existe una forma abstracta de interpretar la ley sobre la edad para contraer matrimonio en las comunidades tanto religiosas como culturales; las 
víctimas del matrimonio infantil son menores de edad y ante la ley son incapaces de llevar a cabo algún procedimiento judicial por sí solos, además de que para llevar a cabo uno, requieren de dinero ante la falta por parte del Estado de medios para poderlos apoyar.

Otro factor de desventaja es que el matrimonio infantil se da más en zonas rurales con poca accesibilidad a la información y el servicio de protección judicial, en la mayor parte de los casos de matrimonio infantil se dan fuera del patrón que normalmente se sigue por lo que no hay registros civiles de dicho matrimonio y por último y no menos importante nos encontramos con que la legislación tiene dificultades, es algo contradictoria y a la vez causa conflicto al momento de definir y regular el matrimonio (Girls not brides, 2016).

Acelerar el proceso de la erradicación del matrimonio infantil debe ser uno de los mayores objetivos el desafío es verdaderamente grande, pero con perseverancia, voluntad y trabajo en equipo, dentro de unos años lograremos erradicar esta problemática, suena lo suficiente ambiciosa, pero reescribir un mejor futuro para nuestros niños $\mathrm{y}$ adolescentes también es parte de nosotros.

Algunos países han ratificado y firmado acuerdos y aunque esto muestre la voluntad de participación no es lo suficiente si no crean leyes precisas en la materia que garantice los derechos de las niñas y niños.

\section{El caso Tabasco.}

De acuerdo a las políticas públicas implementadas por el gobierno federal y con el fin de evitar el matrimonio entre niños, Tabasco modificó su Código Civil en 2008 y estableció en el artículo 154 (Diputados, 2019) que sólo pueden contraer matrimonio el hombre y la mujer que hayan cumplido dieciocho años de edad. La falta de edad requerida por la ley es considerada un impedimento para celebrar el acto jurídico. Asimismo, no considera dispensa o establece alguna excepción.

Empero, el Código Civil también regula la figura del concubinato el cual existe cuando una pareja de hombre y mujer, sin impedimento para contraer matrimonio viven juntos públicamente como si fueran marido $\mathrm{y}$ mujer, durante un año, o menos si 
hubiere hijos; es importante destacar que no es necesaria la validación por parte de un representante del Estado, sólo se requiere que las partes decidan iniciar una vida en común y exhibirse como si fueran matrimonio para que se establezca la figura.

Al momento de la reforma en Tabasco, de los 11 mil 893 matrimonios que se registraban durante un año, 51 casos estaban relacionados con hombres y mujeres menores de 15 años. En el primer semestre de 2016, de los 400 matrimonios celebrados, al menos seis fueron entre menores de edad.

Antes de la reforma, la legislación establecía que podían contraer matrimonio el hombre y la mujer que hubieran cumplido dieciocho años de edad; sin embargo, el gobernador o el presidente municipal del lugar podían conceder una dispensa en casos excepcionales y por causas graves y justificadas aún y cuando no sean mayores de edad. Esto daba lugar a que, en algunos delitos como el estupro, la forma de reparación del daño era el matrimonio.

El estupro es establecido en el Código Penal del estado de Tabasco (Diputados, 2019) como la cópula con mujer mayor de catorce años, pero menos de dieciocho, que no haya alcanzado su normal desarrollo psicosexual, además de que debe mediar el engaño. Para que se considere violación, es necesario que la menor no tenga la suficiente madurez psicosocial, la capacidad para comprender el significado del hecho o por cualquier causa no pueda resistirlo; además de que, si se trata de una menor de 14 años, se privilegia la autodeterminación de la voluntad.

Lo anterior es importante, porque además de la forma tradicional de matrimonio, el concubinato es una figura que permite en cierta forma que se realice la unión entre personas adultas con menores de edad; pero se establece la edad de 14 años como mínima para realizar un fraude a la ley penal, ya que en caso contrario podría dar lugar a un delito grave como es la violación.

Con el concubinato se buscó el reconocimiento de la familia formada de hecho, más no de derecho puesto que, en muchas ocasiones, las responsabilidades que derivan del matrimonio, no quieren ser enfrentadas por las parejas. Solo se requiere el transcurso de un año para que se equipare al matrimonio. 


\section{El Código Civil del Estado de}

Tabasco (2019) establece en el artículo 23 que la familia está formada por las personas que, estando unidas en matrimonio, concubinato o por lazos de parentesco por consanguinidad, afinidad o civil, que habiten en una misma casa o tengan parte en la administración del hogar.

Durante mucho tiempo estuvo en discusión la naturaleza jurídica de las personas de género distinto que constituían una familia sin recurrir a las autoridades del Estado; por ello, éste último les otorgó su reconocimiento, naciendo de esta manera el concubinato, cuya finalidad es idéntica al matrimonio, pero que adopta forma y denominación distinta.

El año pasado, en mayo de 2019, una joven de 14 años acudió a una oficialía del registro civil y solicitó que se le permitiera casarse con su novio de 17 años. Los autores de este artículo, al platicar con ella, narró que cumplió los catorce años en enero y en febrero había decidido unir su vida a la de él y por ello, desde hacía cuatro meses vivía con su pareja en casa de los papás de éste. Al preguntarle sobre las razones por las cuales acudía ante el oficial del Estado, ella respondió que quería regularizar su unión, pues consideraba que era el hombre de su vida y al que había elegido para establecer una familia hasta que la muerte los separara. Es de resaltarse que los padres de la menor, que los acompañaban en ese instante explicaron que ya había hablado con ella y esa era su decisión. Al preguntarles sobre su educación, el papá indicó que ya le habían dicho, pero ella insistía en que era el hombre de su vida y no quería perderlo, por lo que tratarían de apoyarla para que siguiera estudiando, aunque existía una alta posibilidad de que no siguiera en la escuela por dedicarse a atender al muchacho que se desempeñaba como albañil. Ante esa situación y al no poder cumplir con lo solicitado por la peticionaria, el oficial del Registro Civil los canalizó a una instancia jurisdiccional para que ésta a su vez elaborara un acta en la que se plasmara la voluntad de la menor.

\section{Conclusión}

El matrimonio infantil es un gran problema que afecta al niño o adolescente, en consecuencia, también desencadena una serie de repercusiones sociales y económicas. El niño no se desarrolla ante la sociedad de la misma manera, avanzar se vuelve una carga y de 
una $\mathrm{u}$ otra manera debe adaptarse $\mathrm{y}$ conllevar su vida. Por lo que es necesario aumentar los programas de educación, donde se les hable del tema a los niños y adolescentes logrando de esta manera crear jóvenes y personas empoderadas de si, llenas de conocimiento para que sean ellos mismos quienes tengan la libertad de elegir el cuándo y con quien iniciar en un determinado momento lo que es el matrimonio.

Además, parece necesario informar a las comunidades del gran problema que es el matrimonio infantil y así incentivarlos a la oposición de este factor, la lucha debe ser constante pues se busca erradicar con este problema social.

De igual forma se realiza la siguiente propuesta:

1.-Enseñarles a los niños $\mathrm{y}$ adolescentes para que tengan conocimiento del tema. Informar siempre a los niños y adolescentes del problema nos da la ventaja de crear personas con conocimiento, generar ideas de que hacer en caso de encontrase ante tal situación, pero sobre todo crear jóvenes empoderados de su propia persona con la capacidad de decidir libremente su vida y sus interacciones con la sociedad.

2.-Concientizar a la sociedad para que denuncien este delito. El objetivo de esta estrategia es que las personas tengan el conocimiento de lo que afecta el contraer matrimonio con niños (as) y adolescentes, ya que esta situación en realidad depende de las personas adultas, de la sociedad o comunidad y de la familia de las propias víctimas.

3.- Prestar atención especializada a las víctimas. El matrimonio infantil afecta a la víctima de diversas formas ya sea física, psicológica, social, en la educación y en otras ramas mas, donde no se puede desarrollar normalmente; por lo que es necesario prestarles atención especializada que les ayude con el trauma o el daño ocasionado ya se psicológico o de salud, logrando así la reinserción de la persona ante la sociedad.

4.-Educar sexualmente a los jóvenes. Hablarles a los jóvenes ya sea en la escuela y en campañas especiales acerca de su sexualidad y la forma en que deben conllevar diversas situaciones que pudiesen presentarse a lo largo de su 
vida, evitando así infecciones de transmisión sexual y embarazos no deseados.

5.-Marco jurídico y normativo que incluya y siga de cerca el problema. Se requiere la intervención jurídica en este caso, ya que nos hablamos de un delito, por lo que es necesario que se regule y que se promueva el respeto, la equidad, la toma de decisiones y equidad de género que son derechos que se violentan, así como también regular mayor servicio jurídicamente como servicios de salud a las víctimas del delito. Por lo que se deben fortalecer el marco normativo y cumplir las leyes en su totalidad.

$\begin{array}{clll}\text { 6..-Incentivar } & \text { a } & \text { las } \\ \text { comunidades haciendo } & \text { crecer } & \text { la }\end{array}$
economía. Al haber incentivos en la comunidad y la economía en crecimiento se pretende reducir la presión tanto social como económica que viven muchas familias, evitando así que los niños (as) se casen antes de los 18 años.

Pues al haber una economía fluyente no será necesario comercializar o sacar provecho del matrimonio del niño o adolescente.

\section{Bibliografía}

Abundis Rosales, M., \& Ortega Solis, M. (2010). Matrimonio y Divorcio: antecedentes históricos y evolución legislativa. México: Universidad de Guadalajara.

Baqueiro, E. (1997). Derecho de Familia y Sucesiones. México: Harla.

Barros Álvarez, V. (2001). El matrimonio en el mundo actual. Chile: Universidad de Chile.

Carbonell, M. (2006). Familia, Constitución y $\quad$ Derechos Fundamentales. En R. Álvarez de Lara, Panorama Internacional de Derecho de Familia, Cultura y Sistemas Jurídicos Comparados (págs. 81-82). México: UNAM.

CorteIDH. (2002). Opinión Consultiva OC-17/2002. Condición jurídica y Derechos Humanos del Niño. San José, C. R.: Corte Interamericana de Derechos Humanos.

Cuadrado, Á. (2017). El Delito de Matrimonio Forzado. En E. Pérez, El derecho ante las formas contemporáneas de esclavitud (págs. 495-513). España: Tirant lo Blanch. 
Periódico do Núcleo de Estudos e Pesquisas sobre Gênero e Direito

Centro de Ciências Jurídicas - Universidade Federal da Paraíba V. 9 - $\mathrm{N}^{\mathrm{o}} 01$ - Ano 2020 - Spanish Edition

ISSN | 2179-7137 | http://periodicos.ufpb.br/ojs2/index.php/ged/index
Diputados. (2019). Código Civil

Federal. México: Cámara de Diputados del H. Congreso de la Unión.

Diputados. (2019). Código Civil para el Estado Libre y Soberano de Tabasco. Villahermosa: H. Congreso del Estado de Tabasco.

Diputados. (2019). Código Penal para el Estado de Tabasco. Villahermosa: $\mathrm{H}$. Congreso del Estado de Tabasco.

Galindo, I. (1989). Derecho Civil. Primer Curso, Parte general, Personas, Familia. México: Porrúa.

García Gómez, M. (2017). Matrimonio infantil en México: discriminación de género. Pluralidad y consenso, 134-147.

Girls not brides. (2016). El Rol de los parlamentarios en la erradicación del matrimonio infantil. Londrés: Girls not brides.

Hernández, L. (2012). El matrimonio. Obtenido de Temas de Derecho: https://temasdederecho.wordpress.com/t ag/evolucion-historica-del-matrimonio/

INEGI. (11 de noviembre de 2019). Encuesta Nacional de la Dinámica Demográfica (ENADID). Obtenido de
INEGI:

https://www.inegi.org.mx/contenidos/pr ogramas/enadid/2018/doc/resultados_en $\mathrm{ad}$

Kánter Coronel, I. (2018). Matrimonio infantil y uniones tempranas en México. Mirada Legislativa No. 141, 34.

Lisa, M. (Febrero de 2017). El Matrimonio Infantil en México y sus implicaciones en las Niñas y Adolescentes. Obtenido de Suprema Corte de Justicia de la Nación: https://www.scjn.gob.mx/sites/default/fi les/igualdad-genero/201702/MencionEspecial2Ensayo_2013.pdf

Navarrete, P. (2017). El drama del matrimonio de niñas en México. Todas Abril, 2.

Plan Internacional. (2015). Los datos al descubierto: estudio sobre el matrimonio infantil en Asia. Londres: Coram Internacional.

Plan Internacional. (2015). Países donde se practica el matrimonio infantil. Londres: Coram Internacional. Obtenido de Plan Internacional. 
UN. (2016). Reglas mínimas de las

Naciones Unidas para la Administración de la Justicia de Menores (Reglas de Beijing). En UN, Recopilación de Reglas y Normas de las Naciones Unidas en la esfera de la prevención del delito y la justicia penal (págs. 127-151). Nueva York: Naciones Unidas.

UNICEF. (2006). Convención sobre los Derechos del Niño. Madrid: Unicef Comité Español.

UNICEF. (s.f.). Matrimonio infantil. Obtenido de UNICEF: https://www.unicef.org/spanish/protecti on/files/FactSheet_childmarriage_sp.pd $\mathrm{f}$

Williamson, N. (2013). Maternidad en la niñez. Nueva York: Fondo de Población de las Naciones Unidas. 